\title{
Integração de pAN7-1 no Genoma de Magnaporthe grisea Mediada por Enzima de Restrição*
}

\author{
Carlos E. Marchi' ${ }^{1}$, Sérgio H. Brommonschenkel ${ }^{1}$, Marisa V. de Queiroz ${ }^{2}$ \\ \& Eduardo S. G. Mizubuti ${ }^{1}$ \\ ${ }^{1}$ Departamento de Fitopatologia; ${ }^{2}$ Departamento de Microbiologia, Universidade Federal de Viçosa, \\ CEP 36570-000, Viçosa, MG, e-mail: shbromo@ufv.br
}

(Aceito para publicação em 12/05/2006)

Autor para correspondência: Sérgio H. Brommonschenkel

MARCHI, C.E., BROMMONSCHENKEL, S.H., QUEIROZ, M.V. de \& MIZUBUTI, E.S.G. Integração de pAN7-1 no genoma de Magnaporthe grisea mediada por enzima de restrição. Fitopatologia Brasileira 31:254-260. 2006.

\section{RESUMO}

Visando explorar a mutagênese insercional em Magnaporthe grisea, foram avaliadas a transformação dos protoplastos obtidos após adequação do protocolo e a eficiência da integração de pAN7-1 no genoma do ascomiceto na presença da enzima de restrição Hind III. Os protoplastos de M. grisea I-22 foram prontamente transformados para a resistência à higromicina. Quando o vetor linearizado com Hind III foi usado para transformar o fungo na presença de Hind III, a eficiência de transformação foi 1,1 a 8,1 vezes superior ao tratamento sem a adição da enzima. No geral, a melhor concentração de Hind III foi 5 unidades/reação de transformação. Tal concentração promoveu a produção média de 332 transformantes/ $\mu \mathrm{g}$ de pAN7-1/107 protoplastos. A presença do gene de seleção $h p h$ no genoma de 18 indivíduos resistentes à higromicina foi confirmada por PCR.

Palavras-chave adicionais: Pyricularia grisea, P. oryzae, brusone, transformação de fungos, integração mediada por enzimas de restrição, REMI.

\begin{abstract}
Integration of pan7-1 into the Magnaporthe grisea genome mediated by restriction enzyme

To investigate insertional mutagenesis in Magnaporthe grisea, we tested the transformation of protoplasts produced after protocol optimization, and analyzed the integration efficiency of pAN7-1 into the M. grisea genome mediated by the restriction endonuclease Hind III. The I-22 protoplasts were readily transformed for hygromycin resistance. When pAN71 was linearized with Hind III and used to transform fungal protoplasts in the presence of the corresponding enzyme, the transformation efficiency was increased 1.1 to 8.1 -fold. The optimal Hind III concentration for enhanced transformation corresponded to 5 unit/transformation mix. This concentration led to average frequency of 332 transformants/ $\mu \mathrm{g}$ de pAN7$1 / 10^{7}$ protoplasts. The presence of selection gene $h p h$ in the 18 transformant genome was confirmed by PCR.

Additional keywords: Pyricularia grisea, P. oryzae, brusone, fungi transformation, restriction enzyme-mediated integration, REMI.
\end{abstract}

\section{INTRODUÇÃO}

Os vetores para a transformação de fungos filamentosos se integram predominantemente no genoma do hospedeiro via eventos de recombinação (Riach \& Kinghorn, 1996; Mullins \& Kang, 2001). Em geral, integrações de vetores sem homologia com o DNA do fungo ocorrem em sítios ectópicos no genoma, o que permite a utilização dessas moléculas para interromper e marcar fisicamente genes de interesse (Mullins et al., 2001; Recorbet et al., 2003), estratégia esta denominada de "mutagênese insercional mediada por transformação (MIMT)".

Em fungos fitopatogênicos, MIMT tem sido amplamente explorada para a identificação e clonagem de

*Parte da Tese de Doutorado do primeiro autor. Universidade Federal de Viçosa. 2003. genes (Talbot \& McCafferty, 1997; Idnurm \& Howlett, 2001). Tomando como exemplo os genes de patogenicidade listados por Idnurm \& Howlett (2001), constata-se que cerca de $25 \%$ foram identificados a partir de MIMT. Seguramente, a contribuição dessa tecnologia aumentou nos últimos anos, sobretudo com o desenvolvimento de sistemas de transformação mediados por Agrobacterium tumefaciens (Smith \& Towsend) Conn (De Groot et al., 1998).

O estabelecimento de programas de MIMT em Magnaporthe grisea (T.T. Hebert) M.E. Barr, o patógeno mais destrutivo da cultura do arroz, foi inicialmente limitado pela baixa eficiência de transformação usualmente alcançada (Valent \& Chumley, 1991). Em anos recentes, entretanto, a freqüência de transformantes aumentou com o uso de enzimas de restrição para mediar a integração do DNA transformante (Schiestl \& Petes, 1991). A técnica REMI 
(Restriction Enzyme-Mediated Integration), como ficou conhecida, aumentou a freqüência de integração do vetor pAN7-2 no genoma de $M$. grisea, acima de 10 vezes, quando as enzimas de restrição BamHI ou $B g l \mathrm{II}$ foram utilizadas (Shi et al., 1995). Menor freqüência de transformantes foi verificada quando HindIII mediou a integração do vetor (Shi et al., 1995).

As características de REMI, como transformação eficiente e predominância de eventos simples de integração, têm estimulado o uso desta técnica na investigação de genes envolvidos na patogenicidade de M. grisea (Shi et al., 1995; Sweigard et al., 1998; Balhadère et al., 1999; Fujimoto et al., 2002). Contudo, mutantes REMI com patogenicidade alterada não têm sido obtidos com pAN7-1, talvez pela baixa taxa de integração no genoma de $M$. grisea obtida com a adição de enzimas de restrição. Em Mycosphaerella zeae-maydis Mukunya \& Boothr., por exemplo, a eficiência de REMI variou com o tipo de vetor empregado e foi insatisfatória com pAN7-1 (Yun et al., 1998). Esse vetor tem sido amplamente empregado para a transformação de fungos filamentosos, sobretudo ascomicetos, por apresentar tamanho relativamente pequeno e assim proporcionar maiores chances de sucesso no processo de recuperação das seqüências dos genes inativados.

Apesar da contribuição da MIMT para a prospecção de genes envolvidos na patogênese de M. grisea, o conhecimento do repertório de genes envolvidos nos diferentes estágios da patogênese é ainda restrito. A compreensão mais detalhada dos genes que controlam esses mecanismos pós-penetração é de fundamental importância para o desenvolvimento de estratégias eficientes de manejo da brusone do arroz.

Em face do potencial de REMI em suprir a carência de mutantes com defeitos em genes que controlam eventos pós-penetração em arroz, iniciou-se uma série de estudos visando estabelecer as condições de REMI que maximizam a obtenção de mutantes com eventos simples de integração no genoma deste fungo. Como primeiro passo, recentemente, foi otimizado o protocolo de protoplastização do ascomiceto (Marchi et al., 2006). Neste trabalho verificou-se a possibilidade de transformar os protoplastos obtidos segundo esse protocolo e determinou-se a freqüência de integração de pAN7-1 no genoma do fungo mediada pela endonuclease de restrição HindIII.

\section{MATERIAL E MÉTODOS}

\section{Magnaporthe grisea e condições de cultivo}

Foi utilizado o isolado monospórico I-22 de $M$. grisea, obtido a partir de plantas de arroz (Oryza sativa L.), e gentilmente cedido pelo Laboratório de Fitopatologia Molecular da Universidade Federal do Rio Grande do Sul, Porto Alegre, RS.

O fungo foi cultivado em meio de farinha de arrozágar (FAA - $20 \mathrm{~g}$ de farinha de arroz com casca, $5 \mathrm{~g}$ de sacarose, $15 \mathrm{~g}$ de ágar, $1 \mathrm{~L}$ de água destilada) por cinco a sete dias, em BOD a $28-30{ }^{\circ} \mathrm{C}$ no escuro. Para a preservação do fungo em longo prazo, pedaços $\left(4 \mathrm{~cm}^{2}\right)$ de papel manteiga colonizados pelo micélio foram mantidos a $-80^{\circ} \mathrm{C}$ (Valent et al., 1991).

\section{Vetor de transformação pAN7-1}

A transformação de $M$. grisea foi realizada com o plasmídeo pAN7-1, que possui 6,75 Kb (Figura 1). O gene $h p h$, que codifica para a resistência ao antibiótico higromicina $\mathrm{B}$, constitui a marca de seleção de pAN7-1. $h p h$ está fusionado ao promotor do gene da gliceraldeído 3-fosfato desidrogenase e a seqüência terminadora do gene trpC de Aspergillus nidulans (Eidam) G. Winter (Punt et al., 1987).

\section{Curva de sensibilidade de $M$. grisea $\mathbf{I}-22$ à higromicina}

Magnaporthe grisea I-22 foi cultivado em placas de Petri contendo meio FAA acrescido de higromicina em concentrações que variaram de 0 a $350 \mu \mathrm{g} / \mathrm{mL}$. Foram utilizadas seis repetições (placas de Petri) por tratamento, e as placas de Petri foram mantidas por seis dias em BOD a $28-30{ }^{\circ} \mathrm{C}$ no escuro A sensibilidade ao antibiótico foi estimada com base no crescimento micelial (área da colônia $\mathrm{em} \mathrm{cm}^{2}$ ).

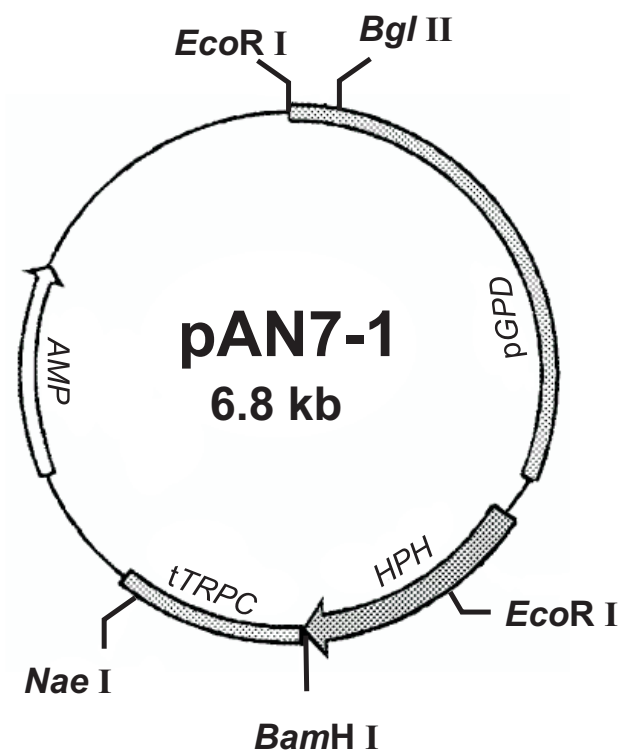

FIG. 1 - Mapa do vetor de transformação pAN7-1 (Punt et al., 1987). O gene $A M P$ (que confere resistência à ampicilina), e o gene da fosfotransferase da higromicina $(H P H)$ de Escherichia coli (que confere resistência à higromicina) constituem os sistemas de seleção para os organismos procarioto e eucarioto, respectivamente. $H P H$ está ligado ao promotor do gene GPD (gliceraldeído-3-fosfato desidrogenase) e ao terminador do gene para a biossíntese de triptofano (tTRPC) de Aspergillus nidulans. Sítios de reconhecimento para enzimas de restrição são indicados. A origem de replicação, necessária para a manutenção e replicação do plasmídeo em $E$. coli, não está representada. 


\section{Produção de protoplastos de $M$. grisea}

Os protoplastos foram obtidos segundo o protocolo de Marchi et al. (2006). Brevemente, misturaram-se $100 \mathrm{mg}$ de micélio úmido a $3 \mathrm{~mL}$ de estabilizador osmótico $\mathrm{MgSO}_{4}$ a $1,2 \mathrm{M} / \mathrm{NaH}_{2} \mathrm{PO}_{4}$ a $0,01 \mathrm{M}(\mathrm{pH} 5,8)$ contendo $10 \mathrm{mg}$ de Lysing Enzymes (Sigma Chemicals Co.) e $10 \mathrm{mg}$ de Cellulase Onozuka R10 (Yakult Biochemical Co. Ltd.). Após 3 h de agitação a $100 \mathrm{rpm}$, a $30{ }^{\circ} \mathrm{C}$, a suspensão de protoplastos foi colocada em tubo corex $(15 \mathrm{~mL})$ e, suavemente, adicionaram-se $4 \mathrm{~mL}$ de estabilizador ST (sorbitol a 0,6 $\mathrm{M}$, Tris- $\mathrm{HCl}$ a $0,1 \mathrm{M}, \mathrm{pH}$ 8,0). Após centrifugação em rotor de caçamba (3000 rpm por $5 \mathrm{~min}$ ), os protoplastos se agregaram na interface dos estabilizadores osmóticos. Os protoplastos foram transferidos para outro tubo corex e 2 $\mathrm{mL}$ de estabilizador STC (sorbitol a $1 \mathrm{M}$, Tris- $\mathrm{HCl}$ a $0,05 \mathrm{M}$, $\mathrm{CaCl}_{2}$ a $0,05 \mathrm{M}, \mathrm{pH} 8,0$ ) foram adicionados. Os protoplastos foram precipitados por centrifugação a $5000 \mathrm{rpm}$ por $10 \mathrm{~min}$ e, em seguida, lavados três vezes em STC. Os protoplastos foram ressuspendidos em STC para a concentração final de $10^{7} / \mathrm{mL}$.

\section{Transformação de $M$. grisea}

A integração de pAN7-1 no genoma de $M$. grisea foi avaliada na ausência ou presença de HindIII. Optou-se por esta enzima de restrição devido aos resultados satisfatórios obtidos em outros sistemas envolvendo o mesmo vetor de transformação (Akamatsu et al., 1997; Linnemannstöns et al., 1999).

A transformação foi conduzida em microtubo de 1,5 $\mathrm{mL}$, onde $1 \mu \mathrm{g}$ de pAN7-1, suspenso em $150 \mu \mathrm{L}$ de SaTC (sacarose $20 \%$, Tris- $\mathrm{HCl}$ a $0,05 \mathrm{M}, \mathrm{CaCl}_{2}$ a $0,05 \mathrm{M}, \mathrm{pH}=$ $8,0)$, foi misturado a $100 \mu \mathrm{L}$ da suspensão de protoplastos ajustada para $10^{7} / \mathrm{mL}$. Quando a reação requereu a presença de HindIII, esta foi simultaneamente adicionada com o pAN7-1-HindIII. A mistura foi homogeneizada e mantida em gelo por $20 \mathrm{~min}$. Após a adição de $1 \mathrm{~mL}$ de solução de polietileno glicol (PEG $335060 \%, \mathrm{CaCl}_{2}$ a $0,025 \mathrm{M}$, Tris- $\mathrm{HCl}$ a $0,025 \mathrm{M}, \mathrm{pH}=7,5$ ) pré-aquecida a $37^{\circ} \mathrm{C}$, efetuou-se nova incubação em gelo por $20 \mathrm{~min}$. O volume foi transferido para tubo corex $30 \mathrm{~mL}$ contendo $12 \mathrm{~mL}$ de meio de regeneração TB3 (sacarose $20 \%$, extrato de levedura $0,3 \%$, caseína hidrolisada $0,3 \%)$ e mantido a $24{ }^{\circ} \mathrm{C}$ sob agitação $(100 \mathrm{rpm})$ por 1 hora. Ao final, dividiu-se o volume entre quatro placas de Petri, onde verteu-se TB3 contendo $2 \%$ de ágar e $300 \mu \mathrm{g}$ de higromicina $/ \mathrm{mL}$. Em seguida, as placas foram mantidas em incubadora a $28-30^{\circ} \mathrm{C}$.

No total realizaram-se cinco ensaios de transformação independentes, em que foram avaliados diferentes tratamentos, a saber: 1) controle, isto é, vetor na forma circular (C); 2) pAN7-1-HindIII, com a inativação da enzima de restrição utilizada para a linearização do vetor (LI), por meio de incubação em banho-Maria a $75^{\circ} \mathrm{C}$ por 15 min; 3) pAN7-1-HindIII, sem inativação da enzima de restrição residual; 4) pAN7-1-HindIII, sem inativação da enzima de restrição residual, com adição de HindIII durante a reação de transformação. Nesse caso, foram utilizadas 5, 10, 20, 30, 40 ou $50 \mathrm{U}$ de enzima de restrição.
Para a linearização do vetor utilizaram-se $10 \mathrm{U}$ de HindIII/ $\mu \mathrm{g}$ de pAN7-1, e a reação permaneceu em banho-Maria a $37{ }^{\circ} \mathrm{C}$ por $2 \mathrm{~h}$.

\section{Extração de DNA}

O fungo foi cultivado em meio completo $(0,5 \%$ de sacarose, $0,3 \%$ de extrato de levedura, $0,3 \%$ de caseína hidrolisada), sob agitação (130 - $150 \mathrm{rpm})$ durante dez-14 dias a $28^{\circ} \mathrm{C}$, no escuro. O micélio produzido, após secagem, foi macerado em nitrogênio líquido. Fração do macerado foi transferida para tubo de microcentrífuga e misturada com $750 \mu \mathrm{L}$ de tampão de extração (CTAB a $55 \mathrm{mM}$, Tris a $100 \mathrm{mM}, \mathrm{pH} 8,0$, EDTA a $10 \mathrm{mM}, \mathrm{NaCl}$ a $0,7 \mathrm{M}$ ) e 15 $\mu \mathrm{L}$ de mercaptoetanol. Após incubação a $65^{\circ} \mathrm{C}$ por $30 \mathrm{~min}$, foram acrescentados $500 \mu \mathrm{L}$ de fenol-clorofórmio-álcool isoamílico (25:24:1) e a mistura foi centrifugada por $5 \mathrm{~min}$ a $14.000 \mathrm{rpm}$. A fase aquosa superior foi transferida para outro microtubo, adicionados $500 \mu \mathrm{L}$ de clorofórmio-álcool isoamílico (24:1), e a mistura foi centrifugada novamente. A fase líquida foi transferida para microtubo contendo 750 $\mu \mathrm{L}$ de isopropanol $\left(-20^{\circ} \mathrm{C}\right)$, incubada em gelo por $10 \mathrm{~min} \mathrm{e}$ centrifugada. Em seguida, o precipitado foi lavado duas vezes com $1 \mathrm{~mL}$ de etanol $70 \%\left(-20^{\circ} \mathrm{C}\right)$, seco e ressuspendido em $50 \mu \mathrm{L}$ de tampão TE (Tris a $10 \mathrm{mM}, \mathrm{pH} 8,0$, EDTA a $1 \mathrm{mM}$ ). A concentração do DNA foi estimada por comparação com padrões de DNA. As amostras de DNA foram armazenadas a $-20^{\circ} \mathrm{C}$.

\section{Polymerase Chain Reaction (PCR)}

Dezoito indivíduos resistentes à higromicina foram examinados para a presença do gene de seleção $h p h$. Após a extração, o DNA total foi submetido à amplificação pela técnica de PCR utilizando os oligonucleotídeos específicos $h p h 1$ (CAGCGAGAGCCTGACCTATTGC) e $h p h 2$ (GCCATCGGTCCAGACGGCCGCGC). O programa de amplificação consistiu de um ciclo de desnaturação de 2 min a $95^{\circ} \mathrm{C}$, seguido por 30 ciclos com $1 \mathrm{~min}$ de desnaturação $\left(92{ }^{\circ} \mathrm{C}\right), 60 \mathrm{~s}$ para o anelamento dos oligonucleotídeos a 60 ${ }^{\circ} \mathrm{C}$, e $90 \mathrm{~s}$ de polimerização a $72{ }^{\circ} \mathrm{C}$. Os amplicons foram visualizados em gel de agarose a $1,4 \%$.

\section{RESULTADOS E DISCUSSÃO}

A resposta de $M$. grisea $\mathrm{I}-22$ às crescentes concentrações de higromicina está representada na Figura 2. Embora seja possível a ocorrência de isolados de M. grisea exibindo resistência à higromicina (Leung et al., 1995), I22 apresentou sensibilidade ao antibiótico. O crescimento micelial de I-22 foi totalmente inibido em concentrações superiores a $250 \mu \mathrm{g} / \mathrm{mL}$ (Figura 2).

Determinado o potencial da higromicina como agente de seleção, o isolado I-22 foi submetido à protoplastização e, subseqüentemente, ao processo de transformação. Por segurança, a concentração de $300 \mu \mathrm{g}$ de higromicina $/ \mathrm{mL}$ foi adotada para os ensaios de transformação. Em geral, a concentração do antibiótico usada para a seleção de 
Integração de pAN7-1 no genoma de Magnaporthe grisea mediada...

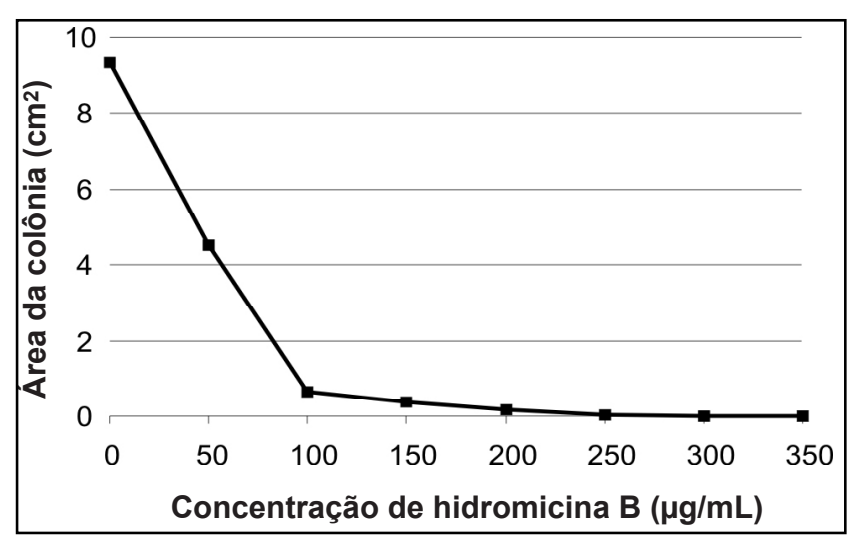

FIG. 2 - Sensibilidade de Magnaporthe grisea I-22 à higromicina $\mathrm{B}$, estimada com base no crescimento micelial (área da colônia em $\mathrm{cm}^{2}$ ) em meio farinha de arroz-ágar acrescido do antibiótico em diferentes concentrações. O valor de área da colônia corresponde a média de seis repetições (placas de Petri), e foi obtido após seis dias de incubação das placas em BOD a $28-30{ }^{\circ} \mathrm{C}$, no escuro.

transformantes de $M$. grisea tem correspondido a 200-300 $\mu \mathrm{g} / \mathrm{mL}$ (Shi et al., 1995; Rho et al., 2001; Viaud et al., 2002; Soanes et al., 2002). A manutenção dos transformantes foi feita em concentração menor, $100 \mu \mathrm{g}$ de higromicina/mL.

Em todos os ensaios de transformação, os protoplastos obtidos segundo o protocolo de Marchi et al. (2006) foram prontamente transformados para a resistência a higromicina (Tabela 1). As primeiras colônias resistentes ao antibiótico foram detectadas após o quarto e quinto dia de incubação.

A análise dos cinco ensaios de transformação permitiu constatar que o número de colônias resistentes à higromicina variou consideravelmente dentro dos tratamentos (Tabela 1). Variações na freqüência de transformantes são comuns entre ensaios de transformação, poucas vezes conseguidose repetibilidade. Analisando a Tabela 1, nota-se que, no geral, todos os tratamentos do ensaio B resultaram em menor produção de transformantes. Isto sugere que diferenças qualitativas e/ou quantitativas nas preparações de protoplastos podem ter contribuído para as oscilações na eficiência de transformação dentro dos tratamentos. Variações na condição fisiológica do micélio utilizado para protoplastização e na quantidade de residual da endonuclease após o tratamento térmico de inativação podem explicar em parte, essas variações de eficiência de transformação de um mesmo tratamento nos diferentes ensaios.

A linearização do vetor elevou a freqüência de transformantes (Tabela 1). O pAN7-1 na forma linear (LI) foi cerca de oito vezes mais eficiente na transformação de $M$. grisea I-22 do que na forma circular (C). Embora o mecanismo não esteja esclarecido, o aumento da eficiência de transformação pela linearização do vetor tem sido demonstrado em outros sistemas como Colletotrichum lindemuthianum (Sacc. \& Magnus.) Briosi \& Cavara. (Redman \& Rodriguez, 1994), Cochliobolus heterostrophus (Drechsler) Drechsler (Lu et al., 1994), Aspergillus oryzae (Ahlb.) E. Cohn. (Yaver et al., 1999) e Penicillium griseoroseum Dierckx (Soares, 2002). Redman \& Rodriguez (1994) acreditam que o vetor linearizado possa ser mais estável ou ter acesso facilitado ao núcleo.

Em todos os ensaios, a eficiência de transformação constatada no tratamento LI foi superior a do tratamento controle (Tabela 1). Não ignorando a condição física do vetor, é provável que o tratamento térmico empregado em LI tenha promovido apenas inativação parcial da enzima utilizada para linearizar pAN7-1. Desta forma, o aumento da eficiência de transformação seria reflexo da atividade enzimática residual. Shi et al. (1995) observaram fenômeno semelhante ao transformarem o isolado Guy $11 \mathrm{de} M$. grisea com pAN7-2. Após a inativação total da enzima, esses autores obtiveram eficiência de transformação com o vetor linear similar a observada com o vetor circular, demonstrando a importância da atividade enzimática residual.

$\mathrm{O}$ efeito positivo da atividade enzimática residual na transformação de $M$. grisea I-22 foi mais evidente no tratamento onde não houve inativação térmica (Tabela 1). Nos ensaios A e B, sem a adição de HindIII na reação de transformação, houve aumento de seis a sete vezes na freqüência de transformantes em relação a LI, respectivamente. Desconsiderando o ensaio $\mathrm{D}$, em média esse aumento correspondeu a 4,9 vezes. Em P. griseoroseum a atividade enzimática residual, XbaI, também afetou positivamente a eficiência de transformação (Soares, 2002).

TABELA 1 - Número de transformantes de Magnaporthe grisea, isolado I-22, obtido com transformação convencional ou mediada por HindIII, utilizando o vetor de transformação pAN7-1

\begin{tabular}{|c|c|c|c|c|c|c|c|c|c|}
\hline \multirow{2}{*}{ Ensaio } & \multirow{2}{*}{$\mathbf{C}^{\mathbf{a}}$} & \multirow{2}{*}{$\mathbf{L I}^{\mathbf{b}}$} & \multicolumn{7}{|c|}{ Unidades de Hind III adicionadas à reação $0^{\mathrm{c}}$} \\
\hline & & & $\mathbf{0}$ & 5 & 10 & 20 & 30 & 40 & 50 \\
\hline $\mathbf{A}$ & $13,3^{\mathrm{d}}$ & 120,0 & 713,3 & $\mathrm{nr}^{\mathrm{e}}$ & $\mathrm{nr}$ & $\mathrm{nr}$ & $\mathrm{nr}$ & $\mathrm{nr}$ & 133,3 \\
\hline B & 3,3 & 11,0 & 72,5 & 85,7 & 89,0 & $\mathrm{nr}$ & $\mathrm{nr}$ & $\mathrm{nr}$ & $\mathrm{nr}$ \\
\hline $\mathbf{C}$ & 34,7 & 55,4 & 108,9 & $\mathrm{nr}$ & 46,9 & $\mathrm{nr}$ & $\mathrm{nr}$ & nr & $\mathrm{nr}$ \\
\hline D & 51,8 & 696,5 & 418,8 & 677,6 & 776,5 & 393,7 & $\mathrm{nr}$ & $\mathrm{nr}$ & $\mathrm{nr}$ \\
\hline $\mathbf{E}$ & 14,1 & 35,9 & 183,7 & 232,6 & 72,8 & 68,5 & 44,6 & 33,7 & 59,8 \\
\hline Média & 23,4 & 183,8 & 299,4 & 332,0 & 246,3 & 231,1 & 44,6 & 33,7 & 96,6 \\
\hline \multicolumn{10}{|c|}{$\begin{array}{l}\text { a pAN7-1 circular. } \\
{ }^{\mathrm{b}} \text { pAN7-1-HindIII. Linearização com } 10 \mathrm{U} \text { de HindIII }\left(37^{\circ} \mathrm{C} / 2 \mathrm{~h}\right) \text { e } \\
\text { posterior inativação da enzima residual }\left(70^{\circ} \mathrm{C} / 15^{\prime}\right) . \\
{ }^{\circ} \text { pAN7-1-HindIII. Linearização com } 10 \mathrm{U} \text { de } \operatorname{Hind} \mathrm{III}\left(37^{\circ} \mathrm{C} / 2 \mathrm{~h}\right) \text {, sem } \\
\text { inativação da enzima residual. }\end{array}$} \\
\hline
\end{tabular}

A integração de pAN7-1 no genoma de $M$. grisea foi influenciada pela adição de HindIII na mistura de transformação. Quando unidades de HindIII foram adicionadas à reação de transformação do fungo com pAN71-HindIII observou-se freqüência de transformantes 1,1 a 8 vezes superior ao LI (Tabela 1). Contudo, para a integração 
de pAN7-2, HindIII apresentou eficiência inferior se comparada a outras enzimas de restrição (Shi et al., 1995). Transformação eficiente de Alternaria alternata (Fr.) Keissl. patótipo do tomate e Gibberella fujikuroi (Sawada) Wollenw. também foi alcançada utilizando pAN7-1 na presença da enzima de restrição HindIII (Akamatsu et al., 1997; Linnemannstöns et al., 1999).

No geral, a adição de $5 \mathrm{U}$ de HindIII por reação de transformação resultou na obtenção de maior número de transformantes, com eficiência de transformação cerca de duas vezes superior ao tratamento controle (LI). É possível que a concentração ótima de HindIII esteja entre 0 e 5 U/reação.

No ensaio A, a adição de $50 \mathrm{U}$ de HindIII na reação promoveu pequeno aumento na produção de transformantes em relação ao tratamento sem adição de enzima (Tabela 1). O último ensaio reproduziu melhor a tendência de declínio na eficiência de transformação quando concentrações elevadas de enzima foram utilizadas. No geral, a adição de mais de cinco unidades de HindIII na reação de transformação reduziu o número de transformantes. Trinta ou quarenta unidades de enzima provocaram queda drástica do número de transformantes (Tabela 1). O efeito negativo de altas concentrações enzimáticas na freqüência de transformantes foi anteriormente verificado em M. grisea (Shi et al., 1995). Quando $600 \mathrm{U}$ de HindIII ou BamHI, por mL de reação, foram utilizadas para mediar a transformação do isolado Guy 11 com pAN7-2, a recuperação de transformantes foi menor do que a obtida com o vetor circular (Shi et al., 1995). Respostas semelhantes têm sido obtidas com outros fungos fitopatogênicos (Akamatsu et al., 1997; Linnemannstöns et al., 1999). Por exemplo, a reação de transformação de $A$. alternata Keissler patótipo do tomate com mais de $20 \mathrm{U}$ de HindIII ou $X b a \mathrm{I}$ promoveu redução significativa no número de transformantes (Akamatsu et al., 1997).

É possível que altas concentrações de enzimas produzam danos genéticos irreversíveis que levam à inviabilidade celular (Riggle \& Kumamoto, 1998). Contudo, Shi et al. (1995) não evidenciaram decréscimo na viabilidade dos protoplastos de $M$. grisea quando altas concentrações de enzimas de restrição foram usadas em procedimentos de transformação sem a presença do vetor, sugerindo que este fungo é capaz de reparar as quebras duplas do DNA causadas pela ação da enzima. Por outro lado, é possível que a clivagem enzimática excessiva ocorra somente quando o DNA transformante está presente (Thon et al., 2000). Além disso, tem sido sugerido que a presença do vetor de transformação é necessária para o acesso da enzima de restrição ao interior do núcleo (Maier \& Shäfer, 1999). Outra possibilidade é a constante atividade da enzima nos sítios de restrição, decrescendo a freqüência de integração do vetor, e conseqüentemente a eficiência de transformação.

Dezoito indivíduos I-22 resistentes ao antibiótico higromicina, amostrados aleatoriamente, foram examinados para a presença do gene de seleção $h p h$. O fragmento esperado de $690 \mathrm{pb}$, correspondente à região estrutural do gene de seleção $h p h$, foi amplificado em todos os 18 indivíduos, confirmando a condição de transformantes (Figura 3).

A presença de HindIII favoreceu a transformação de M. grisea I-22 com pAN7-1. Contudo, antes de pAN7-1 ser utilizado efetivamente como marcador físico na mutagênese REMI, será necessário analisar o padrão de integração no genoma do ascomiceto, bem como a aleatoriedade desses eventos. A inserção de uma única cópia do vetor em cada transformante e a restauração das seqüências reconhecidas pela enzima de restrição facilitam a recuperação dos genes de patogenicidade inativados. A aleatoriedade dos eventos

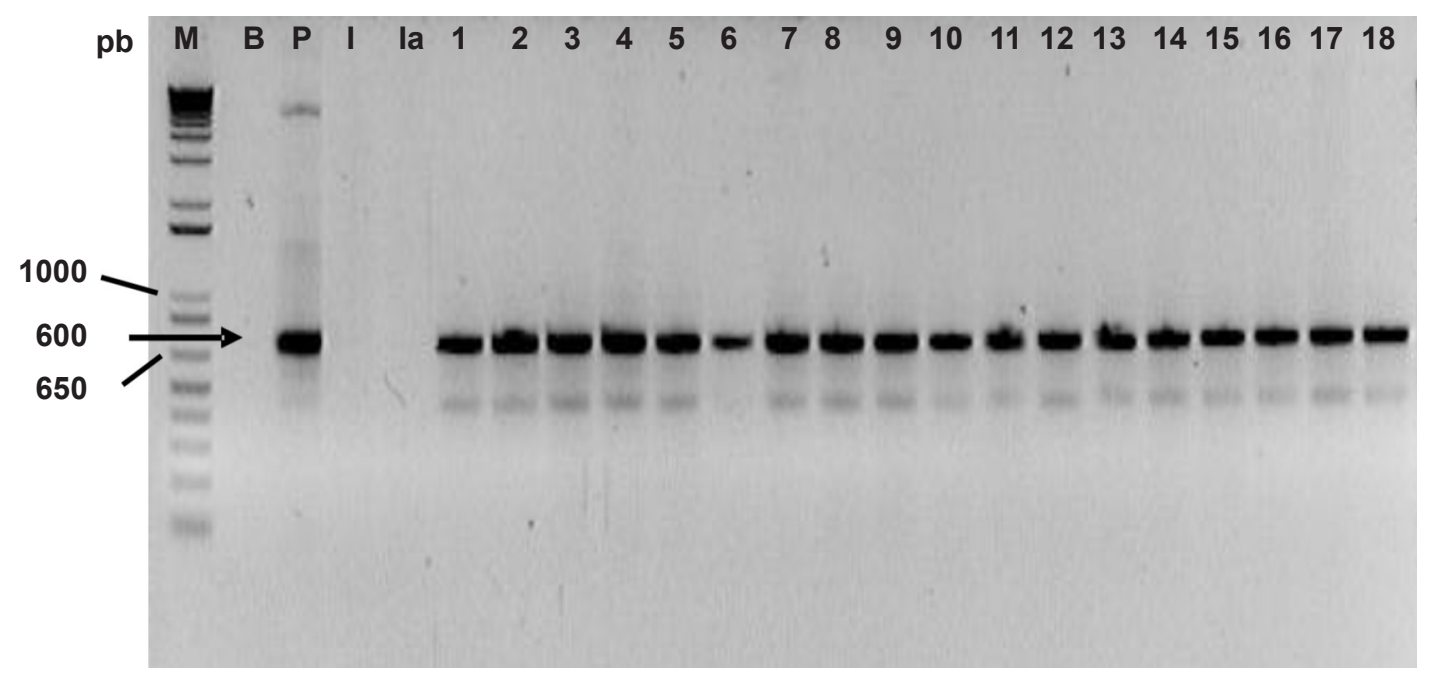

FIG. 3 - Perfil eletroforético dos amplicons de transformantes de Magnaporthe grisea I-22 (1 a 18),

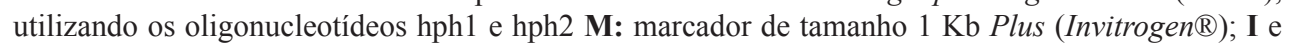
Ia: M. grisea I-22 e I-21, respectivamente; B: reação controle, contendo todos os reagentes, exceto o DNA; P: pAN7-1. Os fragmentos de 1000 e 650 pares de base (pb) do marcador estão indicados na margem esquerda. A seta indica os amplicons de $690 \mathrm{pb}$ esperados. 
Integração de pAN7-1 no genoma de Magnaporthe grisea mediada...

de integração, por sua vez, aumenta a possibilidade de integração em genes de interesse. Análises de hibridização de DNA de transformantes $M$. grisea I-22 estão sendo conduzidas para determinar a freqüência desses eventos.

A eficiência da transformação REMI em $M$. grisea envolvendo pAN7-2 foi dependente do tipo de enzima de restrição (Shi et al., 1995). Portanto, outras enzimas de restrição deverão ser analisadas no sistema M. grisea:pAN71. Além do mais, a alternância de enzimas no programa de mutagênese REMI é interessante porque garante uma distribuição aleatória das integrações e, consequentemente, uma maior abrangência do genoma do organismo em estudo.

\section{REFERÊNCIAS BIBLIOGRÁFICAS}

AKAMATSU, H., ITOH, Y., KODAMA, M., OTANI, H. \& KOHMOTO, K. AAL-toxin-deficient mutants of Alternaria alternata tomato pathotype by restriction enzyme-mediated integration. Phytopathology 87:967-972. 1997.

BALHADÈRE, P.V., FOSTER, A.J. \& TALBOT, N.J. Identification of pathogenicity mutants of the rice blast fungus Magnaporthe grisea by insertional mutagenesis. Molecular Plant-Microbe Interactions 12:129-142. 1999.

DE GROOT, M.J.A., BUNDOCK, P., HOOYKAAS, P.J.J. \& BEIJERSBERGEN, A.G.M. Agrobacterium tumefaciens-mediated transformation of filamentous fungi. Nature Biotechnology 16:839842. 1998.

FUJIMOTO, D., SHI, Y., CHRISTIAN, D., MANTANGHIHAN, J.B. \& LEUNG, H. Tagging quantitative loci controlling pathogenicity in Magnaporthe grisea by insertional mutagenesis. Physiological and Molecular Plant Pathology 61:77-88. 2002.

IDNURM, A. \& HOWLETT, B.J. Pathogenicity genes of phytopathogenic fungi. Molecular Plant Pathology 2:241-255. 2001.

LEUNG, H., LOOMIS, P. \& PALL, M.L. Transformation of Magnaporthe grisea to phosphinothricin resistance using the bar gene from Streptomyces hygroscopicus. Fungal Genetics Newsletter 42:41-43. 1995.

LINNEMANNSTÖNS, P., VOB, T., HEDDEN, P., GASKIN, P. \& TUDZYNSKI, B. Deletions in the gibberellin biosynthesis gene cluster of Gibberella fujikuroi by restriction enzyme-mediated integration and conventional transformation-mediated mutagenesis. Applied and Environmental Microbiology 65:2558-2564. 1999.

LU, S., LYNGHOLM, L., YANG, G., BRONSON, C., YODER, O.C. \& TURGEON, B.G. Tagged mutations at the Tox 1 locus of Cochliobolus heterostrophus by restriction enzyme-mediated integration. Proceedings of the National Academy of Sciences of USA 91:12649-12653. 1994.

MAIER, F.J. \& SCHÄFER, W. Mutagenesis via insertional-or restriction enzyme-mediated-integration (REMI) as a tool to tag pathogenicity related genes in plant pathogenic fungi. Biological Chemistry 380: 855-864, 1999.

MARCHI, C.E., BROMMONSCHENKEL, S.H., QUEIROZ, M. de V., MIZUBUTI, E.S.G. Produção e regeneração de protoplastos de Magnaporthe grisea. Summa Phytopathologica. 2006. "no prelo".
MULLINS, E.D. \& KANG, S. Transformation: a tool for studying fungal pathogens of plants. Cellular and Molecular Life Sciences 58:2043-2052. 2001.

MULLINS, E.D., CHEN, X., ROMAINE, P., RAINA, R., GEISER, D.M. \& KANG, S. Agrobacterium-mediated transformation of Fusarium oxysporum: an efficient tool for insertional mutagenesis and gene transfer. Phytopathology 91:173-180. 2001.

PUNT, P.J., OLIVER, R.P., DINGEMANSE, M.A., POUWELS, P.H. \& VAN DEN HONDEL, C.A.M.J.J. Transformation of Aspergillus based on the hygromicyn B resistance marker from Escherichia coli. Gene 56:117-124. 1987.

RECORBET, G., STEINBERG, C., OLIVAIN, C., EDEL, V., TROUVELOT, S., DUMAS-GAUDOT, E., GIANINAZZI, S. \& ALABOUVETTE, C. Wanted: pathogenesis-related marker molecules for Fusarium oxysporum. New Phytologist 159:73-92. 2003.

REDMAN, R.S. \& RODRIGUEZ, R.J. Factors affecting the efficient transformation of Colletotrichum species. Experimental Mycology 18:230-246. 1994.

RHO, H.S., KANG, S. \& LEE, Y.H. Agrobacterium tumefaciensmediated transformation of the plant pathogenic fungus, Magnaporthe grisea. Molecules and Cells 12:407-411. 2001.

RIACH, M.B.R. \& KINGHORN, J.R. Genetic transformation and vector developments in filamentous fungi. In: Bos, C. J. (Ed.) Fungal genetics: principles and practice. New York. Marcel Dekker Inc. 1996. pp. 209-233.

RIGGLE, P.J. \& KUMAMOTO, C.A. Genetic analysis in fungi using restriction-enzyme-mediated integration. Current Opinion in Microbiology 1:395-399. 1998.

SCHIESTL, R.H. \& PETES, T.D. Integration of DNA fragments by illegitimate recombination in Saccharomyces cerevisiae. Proceedings of the National Academy of Sciences of USA 88:75857589. 1991.

SHI, Z., CHRISTIAN, D. \& LEUNG, H. Enhanced transformation in Magnaporthe grisea by restriction enzyme-mediated integration of plasmid DNA. Phytopathology 85:329-333. 1995.

SOANES, D.M., KERSHAW, M.J., COOLEY, R.N. \& TALBOT, N.J. Regulation of the $M P G 1$ gene in the rice blast fungus Magnaporthe grisea. Molecular Plant-Microbe Interactions 15:1253-1267. 2002.

SOARES, M.A. Transformação e mutagênese insercional em Penicillium griseoroseum por REMI (integração mediada por enzima de restrição) (Dissertação de Mestrado). Viçosa. Universidade Federal de Viçosa. 2002.

SWEIGARD, J.A., CARROLL, A.M., FARRALL, L., CHUMLEY, F.G. \& VALENT, B. Magnaporthe grisea pathogenicity genes obtained through insertional mutagenesis. Molecular Plant-Microbe Interactions 11:404-412. 1998.

TALBOT, N.J. \& McCAFFERTY, H.R.K. Identification and characterisation of pathogenicity genes from the rice blast fungus Magnaporthe grisea. Cahiers Options Méditerranéennes 15:137142. 1997.

THON, M.R., NUCKLES, E.M. \& VAILLANCOURT, L.J. Restriction enzyme-mediated integration used to produce pathogenicity mutants of Colletotrichum graminicola. Molecular Plant-Microbe Interactions 13:1356-1365. 2000. 
VALENT, B. \& CHUMLEY, F.G. Molecular genetic analysis of the rice blast fungus, Magnaporthe grisea. Annual Review of Phytopathology 29:443-467. 1991.

VALENT, B., FARRALL, L. \& CHUMLEY, F.G. Magnaporthe grisea genes for pathogenicity and virulence identified through a series of backcrosses. Genetics 127:87-101. 1991.

VIAUD, M.C., BALHADÈRE, P.V. \& TALBOT, N.J. A Magnaporthe grisea cyclophilin acts as a virulence determinant during plant infection. The Plant Cell 14:917-930. 2002.
YAVER, D.S., LAMSA, M., MUNDS, R., BROWN, S.H., OTANI, S., FRANSSEN, L., JOHNSTONE, J.A. \& BRODY, H. Using DNA-tagged mutagenesis to improve heterologous protein production in Aspergillus oryzae. Fungal Genetics and Biology 29:28-37. 2000.

YUN, S.H., TURGEON, B.G. \& YODER, O.C. REMI-induced mutants of Mycosphaerella zeae-maydis lacking the polyketide PM-toxin are deficient in pathogenesis to corn. Physiological and Molecular Plant Pathology 52:53-66. 1998. 